\title{
Good Governance and Anti-corruption
}

\section{Introducing \\ Citizens' Forum Against Corruption (CFAC)}

Afghanistan Public Policy Research Organization (APPRO)

\author{
www.appro.org.af \\ Kabul - May 29, 2016
}




\section{Anti-corruption Stakeholders}

- "We are all sinners"

- All stakeholders $\rightarrow$ Understand root causes

- Civil Society Organizations $\rightarrow$ Resist and seek protection

- Political parties $\rightarrow$ Put anti-corruption on political agenda

- Donors $\rightarrow$ Mainstream anti-corruption

- Media $\rightarrow$ Mainstream / shape public awareness

- Government:

- Sustain political will and reform with input from civil society

- Use key ministries, i.e., Education, Hajj and Ouqaf

- No more committees!

- Implementation $\rightarrow$ Utilize modern structures, e.g., Rule of Law, and traditional structures, e.g., jirgas, shuras, elders' councils + Youth + CSOs 


\section{Existing Anti-corruption Stakeholders}
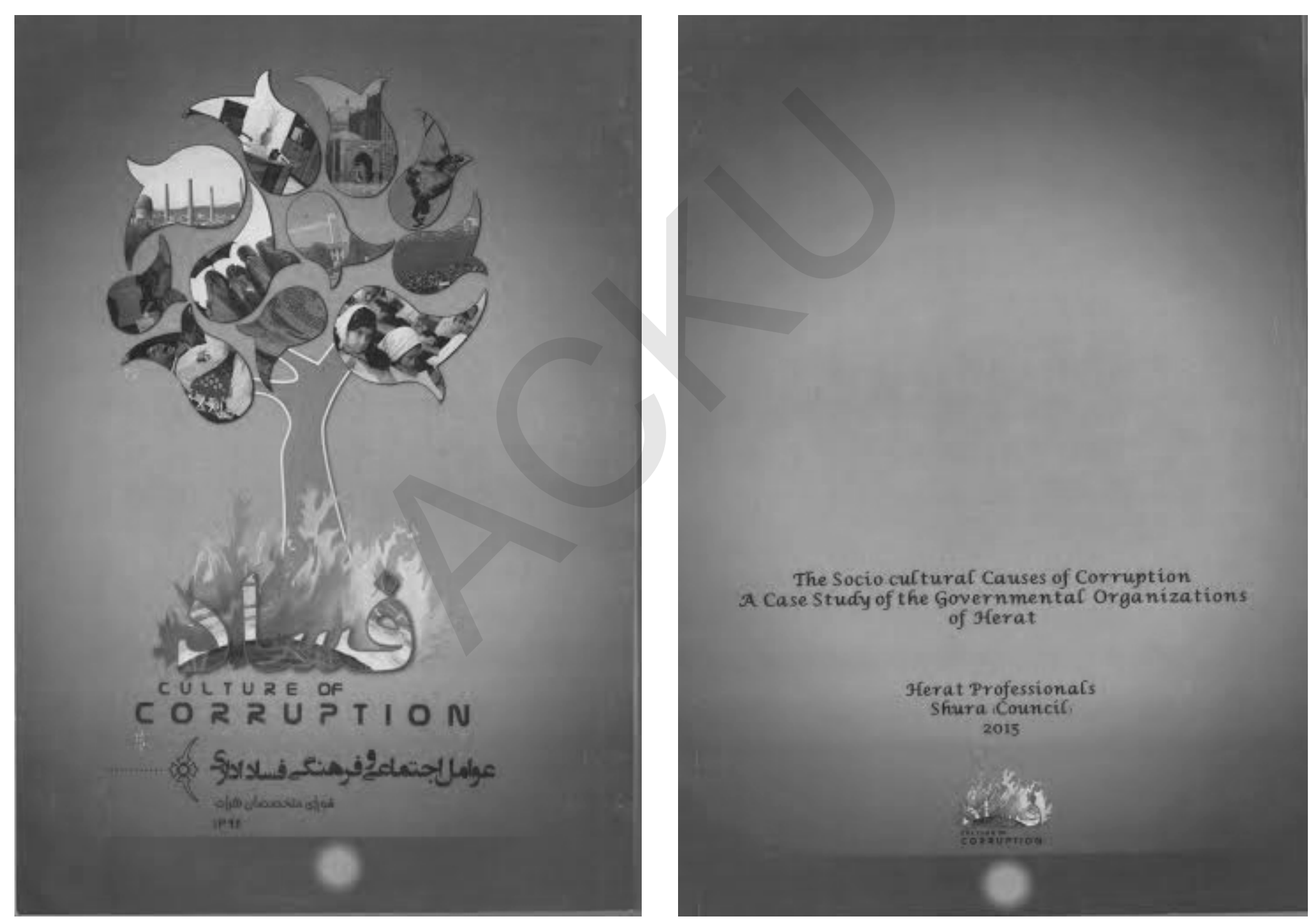


\section{Citizens' Forum Against Corruption}

Members from:

- Public Sector (NGOs, Civil Society, Government)

- Private Sector

- Mission: To resist, reduce, and eliminate extortion by STO, MTO and LTO and effect regulatory and legal reform on anti-corruption with oversight from civil society

- Objectives:

- Adequate and relevant capacity of civil society to fight corruption - Constructive Advocacy

- Create mechanisms for protection of anti-corruption actors:

- Political support

- Tax specialist

- Criminal lawyer 


\section{CFAC Outcomes}

- Better Governance through:

- Increased engagement of civil society in government decision making

- Increased transparency, and

- Increased accountability

- Increased government revenue through, at least, a fourfold increase in taxes from private and public entities:

- Non-profits: around 3,000

- Private sector: ?

- Legitimate expectation of citizens for government services

- Improved government services due to increase in tax revenue 


\section{National Advocacy Committee (NAC) and CFAC}

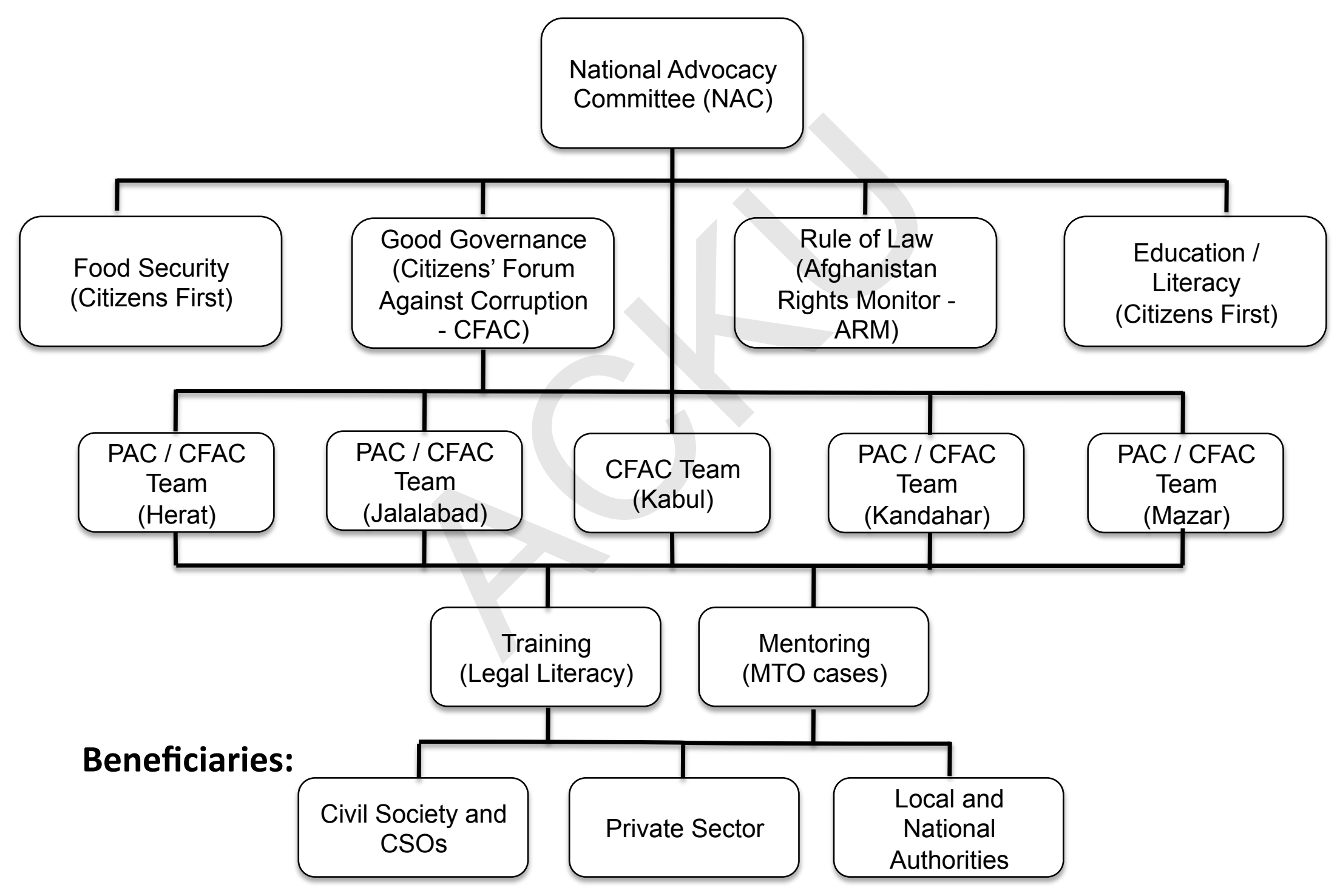




\section{Objectives}

- Identification of capacity needs of CSOs, private sector, and government authorities dealing with corruption.

- Strengthen capacity and awareness of civil society and government authorities about the policy process, constructive advocacy, and legal provisions on anti-corruption.

- Increase accountability, transparency, and thus legitimacy of local and national authorities through constructive cooperation with civil society against corruption. 


\section{Components}

- Component 1: Baseline Assessment and Stock Taking of Corruption

- A baseline assessment of the legislative framework for curbing corruption and stock taking of various manifestations of corruption at the five target sites to develop indicators for tracking corruption

- A stakeholder mapping and analysis at the five target sites to be used for the identification of civil society actors (CSOs and businesses) willing to participate in Citizens' Forum Against Corruption (CFAC)

- Setting up a dedicated website for CFAC. 


\section{Components}

- Component 2: Thematic Research on Corruption and Related Issues

- One thematic paper per year (4 in total) on corruption

- Two (2) policy briefs and three (3) press releases per year on real life experiences of corruption collected through CFAC's website and actual cases of corruption taken on through CFAC

- Annual report highlighting each year's activities, outcomes, challenges, and ways forward.

- Component 3: Establishment of Citizens' Forum Against Corruption (CFAC)

- Today (May 29, 2016) is the start of this process 


\section{Components}

- Component 4: Provision of Legal and Technical Services for Victims of Corruption

- Appointment of a national criminal lawyer to act on behalf of victims of corruption

- Appointment of a national tax expert to assist citizens against extortion by corrupt government officials

- Component 5: Capacity Building on Anti-corruption Advocacy

- Legal literacy on anti-corruption, Access to Information Law, and Tax Law.

- Policy process, evidence-based constructive advocacy, monitoring

- Component 6: Exit Strategy and Sustainability Plan 


\section{Today's Tasks}

- Agreement in principle to share information with CFAC on tax payment challenges

- Commitment to meet once every 6-8 weeks to update and decide on action

- Work with honest MoF and other ministry officials on reform

- Feed information on corruption to media

- Set up and sustain a public awareness campaign

- Other suggestions? 